\title{
Scoping review of acute stroke care management and rehabilitation in low and middle-income countries
}

\author{
George Lameck Chimatiro ${ }^{1,2^{*}}$ (D) and Anthea J. Rhoda ${ }^{1}$
}

\begin{abstract}
Background: Stroke is a major public health concern, affecting millions of people worldwide. Care of the condition however, remain inconsistent in developing countries. The purpose of this scoping review was to document evidence of stroke care and service delivery in low and middle-income countries to better inform development of a context-fit stroke model of care.

Methods: An interpretative scoping literature review based on Arksey and O'Malley's five-stage-process was executed. The following databases searched for literature published between 2010 and 2017; Cochrane Library, Credo Reference, Health Source: Nursing/Academic Edition, Science Direct, BioMed Central, Cumulative Index to Nursing and Allied Health Literature (CINNAHL), Academic Search Complete, and Google Scholar. Single combined search terms included acute stroke, stroke care, stroke rehabilitation, developing countries, low and middle-income countries.
\end{abstract}

Results: A total of 177 references were identified. Twenty of them, published between 2010 and 2017, were included in the review. Applying the Donebedian Model of quality of care, seven dimensions of stroke-care structure, six dimensions of stroke care processes, and six dimensions of stroke care outcomes were identified. Structure of stroke care included availability of a stroke unit, an accident and emergency department, a multidisciplinary team, stroke specialists, neuroimaging, medication, and health care policies. Stroke care processes that emerged were assessment and diagnosis, referrals, intravenous thrombolysis, rehabilitation, and primary and secondary prevention strategies. Stroke-care outcomes included quality of stroke-care practice, functional independence level, length of stay, mortality, living at home, and institutionalization.

Conclusions: There is lack of uniformity in the way stroke care is advanced in low and middle-income countries. This is reflected in the unsatisfactory stroke care structure, processes, and outcomes. There is a need for stroke care settings to adopt quality improvement strategies. Health ministry and governments need to decisively face stroke burden by setting policies that advance improved care of patients with stroke. Stroke Units and Recombinant Tissue Plasminogen Activator (rtPA) administration could be considered as both a structural and process necessity towards improvement of outcomes of patients with stroke in the LMICs.

Keywords: Acute stroke, Stroke care structure, Stroke care process, Stroke care outcomes, Low and middle incomecountries

\footnotetext{
* Correspondence: chimatirogeorge@hotmail.com

'University of the Western Cape, Cape Town, South Africa

${ }^{2}$ Medical Rehabilitation College, Box 256, Blantyre, Malawi
}

(c) The Author(s). 2019 Open Access This article is distributed under the terms of the Creative Commons Attribution 4.0 International License (http://creativecommons.org/licenses/by/4.0/), which permits unrestricted use, distribution, and reproduction in any medium, provided you give appropriate credit to the original author(s) and the source, provide a link to the Creative Commons license, and indicate if changes were made. The Creative Commons Public Domain Dedication waiver (http://creativecommons.org/publicdomain/zero/1.0/) applies to the data made available in this article, unless otherwise stated. 


\section{Background}

Stroke is a major public health concern, both debilitating and deadly to millions of people worldwide each year [1]. Stroke frequently leads to loss of functional independence from physical and cognitive dysfunction. While stroke is stressful, efforts toward better outcomes, such as limiting the disability, more effective means of coping with loss, adaptation to change, and temporal ordering of coping processes could help patients recover to their highest possible functional level [2]. To achieve these outcomes, high quality care is needed. The quality of patient care can be conceptualized using a model, such as the one developed by Donebedian.

\section{Donabedian model (DM): the conceptual framework}

Known as the most comprehensive model for assessing quality of health care [3], as presented in 1966, the model has three distinct aspects to health care quality: structures, processes, and outcomes (SPO) [4]. Accordingly, Structures of health care are defined as the physical and organizational aspects of care settings, for example, facilities, equipment, personnel, operational, and financial processes supporting medical care. Processes in patient care include resources, mechanisms provided by the health care structures to carry out patient-care activities that promote recovery, functional restoration, survival, and patient satisfaction (the Outcomes) [5].

In addition to developing the methodology for measuring structures, processes, and outcomes, Donabedian made an equally important contribution by prioritizing governance and management. When supported by measurement methods, they could be the determining causes of the effectiveness and efficiency of health services [6]. Related to quality of care, Donabedian said "systems ... are enabling mechanisms only. It is the ethical dimension of individuals that is essential to a system's success." [7]. This is in sharp contrast to the ideologies of other researchers who advocated universal coverage or claimed that physicians' clinical and financial autonomy was a precondition for the quality of care [6].

The relationships between structures, processes, and outcomes were effectively presented in a South African study which assessed quality of integrated chronic disease, among patients and operational managers. The study found that structure-related construct was the availability of equipment, supply of critical medicines, and accessibility of chronic disease care. Those related to process were communication between the nurses and patients, attendance of the nurses to patients' health needs, professional conduct of the nurses, nurses' friendliness with patients, hospital referrals for patients, pre-packaging of medicines, physical examination of patients; and the time nurses spent with patients during consultation. Whereas, outcome-related construct included coherence of integrated chronic disease care, competence of nurses, and patients' confidence in nurses [8].

Effective stroke care included assessment (completed within $48 \mathrm{~h}$ post stroke) [9], early mobilization to prevent or reduce complications such as infections, deep vein thromboses (DVT), and falls, and promote recovery [10], avoidance of urinary catheterization, leading to bladder infections [11], treatment of hypoxia, hyperglycemia, and suspected infections [12], and ongoing rehabilitation activities [13]. Internationally, four acute-care intervention processes have been recommended by most stroke experts as the most effective front-line interventions. Those included care in a specialised stroke unit (SU), [14], thrombolytic therapy through tissue plasminogen activator (t-PA) for acute ischemic stroke (within $4.5 \mathrm{~h}$ of initial onset) $[15,16]$, aspirin therapy for acute ischaemic stroke (within $48 \mathrm{~h}$ ) [17], and decompressive surgery (within $48 \mathrm{~h}$ ) [18] to reduce stroke-related mortality and morbidity [19].

As highlighted, the most effective stroke-care service requires an organized setting such as SU care [14]. However, where units do not exist, patients with stroke should be admitted to generic wards, staffed by a coordinated multidisciplinary team with special expertise in stroke care [20]. In some settings in LMICs, such as those in Africa, multidisciplinary stroke-care teams are formed with non-specialist service providers, and in the absence of other equally important professionals, such as speech therapists [21]. There is also a need for readily available radiological equipment to make the most accurate stroke diagnosis [22]. Clinical methods predominate in resource-limited settings, [23], although Imam and Olorunfemi said such methods still need proper attention through a skills check [24]. Accurate diagnosis of stroke related to site, size, and type still requires radiological methods.

It was recommended that appropriate systems of stroke care be established in LMICs to control the increasing death and disability associated with stroke [25, 26]. However, implementation of those systems is challenged by the absence of direct health policy support from the state or national level for stroke care [27].

Applying Arskey and O'Malley's 2005 scoping review methodology [28], the purpose of this review was to systematically document the evidence of stroke care and rehabilitation service provision in LMICs that could inform the development of a more-effective contextual model of care for Malawians and ultimately an improvement in their quality of life.

The following broad question was used to ensure that all relevant literature was included [28],

"What are the components of acute stroke care and rehabilitation services by health personnel across the 
hospital stroke care continuum in LMIC?" This question was delineated to have "stroke care" AND "profession and setting" search terms.

\section{Methods \\ Identifying relevant studies}

According to Joanna Briggs Institute [29], in searching for articles to be included in a scoping review, the researcher undertakes a limited search of relevant databases, followed by analysis of text words from titles, abstracts, and index words. Therefore, this researcher performed an electronic database search that included Cochrane Library, Credo Reference, Health Source: Nursing/Academic Edition, Science Direct, BioMed Central, CINNAHL with full text, Academic Search Complete, and Google Scholar in January 2018. Search tools such as medical subject headings (MESH) and truncation to narrow or expand searches were utilized. Single and combined search terms included acute stroke, stroke care, stroke rehabilitation, developing countries, and LMIC. This study included empirical English articles on stroke care, published between 2010 and 2017. Excluded studies were those from high-income countries using the World Bank definition [30] not within the defined range of publication time, and those covering participants under 18 years of age, per the United Nations Conventions of the Rights of the Child [31].

\section{Selection of articles for inclusion}

The researchers used a two-stage selection criterion [32] (Halas, Schultz, Rothney, Goertzen, Wener, and Katz, (2014). Initially, the researcher and team (GC, SM, FM $\mathrm{HZ}$, and JA) screened the titles and reviewed them for relevance to acute stroke hospital and rehabilitation care from LMICs. Secondly, they screened the chosen articles' abstracts with key sections of the introduction for answers to the research question and objectives, methods that included the article design, setting or context, key findings, and conclusions.

\section{Data charting and collation}

If the article met the inclusion criteria, the information relating to aim of the study was extracted and captured on a data charting form. The data charting table/form as displayed in Table 1 included the citation (author and year), country, recruitment context, study design, sample, outcomes based on objectives, and key findings. The table/form was peer-reviewed, with ambiguity removed in the process. The authors and research assistants (GC, HZ, JA, SM) initially extracted data independently, then met to determine if the data extractions were consistent with the aim of the study and the research questions (Table 1).

\section{Collating, summarizing and reporting findings}

To evaluate the evidence of stroke care in LMICs, the researchers summarized and categorized the data in line with the SPO model as the conceptual framework.

\section{Results}

The search identified 177 articles. Duplicates $(n=27)$ were manually removed. Title and abstract searches revealed 58 articles not within the context of the research question. Seventy-two articles did not meet the inclusion criteria for various reasons, leaving 20 articles for the scoping review (Fig. 1).

Evaluating the evidence on stroke care in the LMICs was facilitated by synthesizing findings of studies describing hospital acute stroke care and rehabilitation. The findings have been displayed, with their general characteristics such as the settings and locations. (Table 1). Various stroke care practices and service limitations have been noted based on conclusions and recommendation towards better practice by the authors. The Donabedian Model identified three primary themes of stroke care which are stroke care structure, process, and outcomes.

\section{Descriptive presentation of results}

The overall aim of this study was to determine the current evidence of stroke care and rehabilitation in LMICs. To achieve this aim, we first needed to understand current stroke care services in the countries that share similar evidence of stroke burden and economic characteristics. Studies from LMICs per the World Bank classification from 2009 and 2017 were included. In addition to noting the number of articles, we recorded general characteristics such as study settings. The findings were further illustrated in three key thematic areas based on the Donabedian model. The results are highlighted by the combination of texts, tables, and figures.

\section{General characteristics of included articles}

There was a total of 20 articles, published between 2009 and 2017. They were from different LMICc, with half [10] of the articles from Africa and the other half [10] from Asia. The design for most of the articles was a retrospective chart review $(n=8)$. Others were systematic reviews $(n=3)$, case report, situational analysis, and descriptive studies $(n=2)$, and 1 each for cross-sectional prospective study, literature review, descriptive studies, prospective follow-up. The focci of the articles was hospital care and rehabilitation services. The topics were categorized into SPO.

\section{Stroke care structures}

This scoping review had 19 dimensions of stroke care, thematically established from 11 articles [33, 34, 38, 40- 
Chimatiro and Rhoda BMC Health Services Research

(2019) 19:789

Page 4 of 15

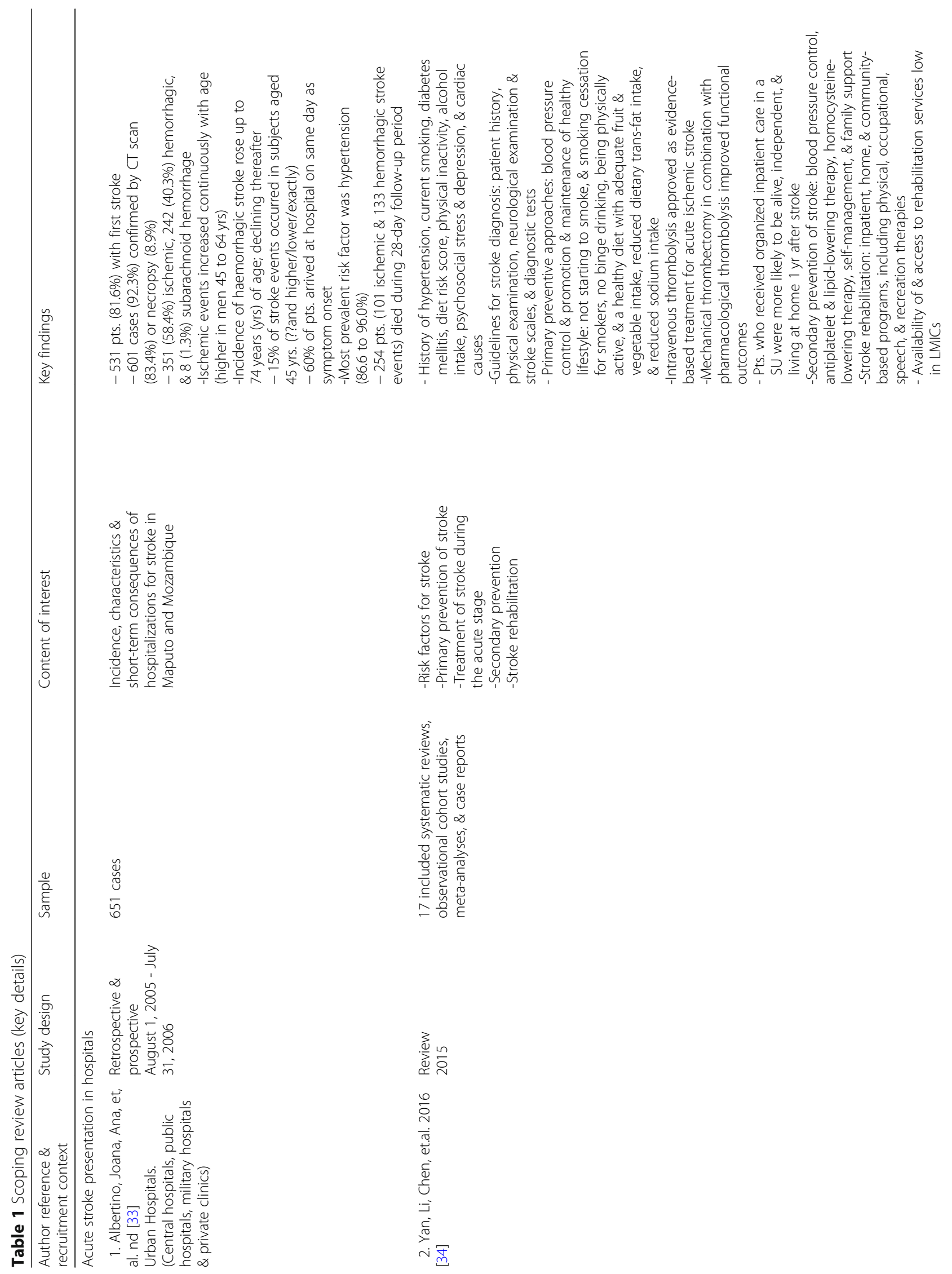




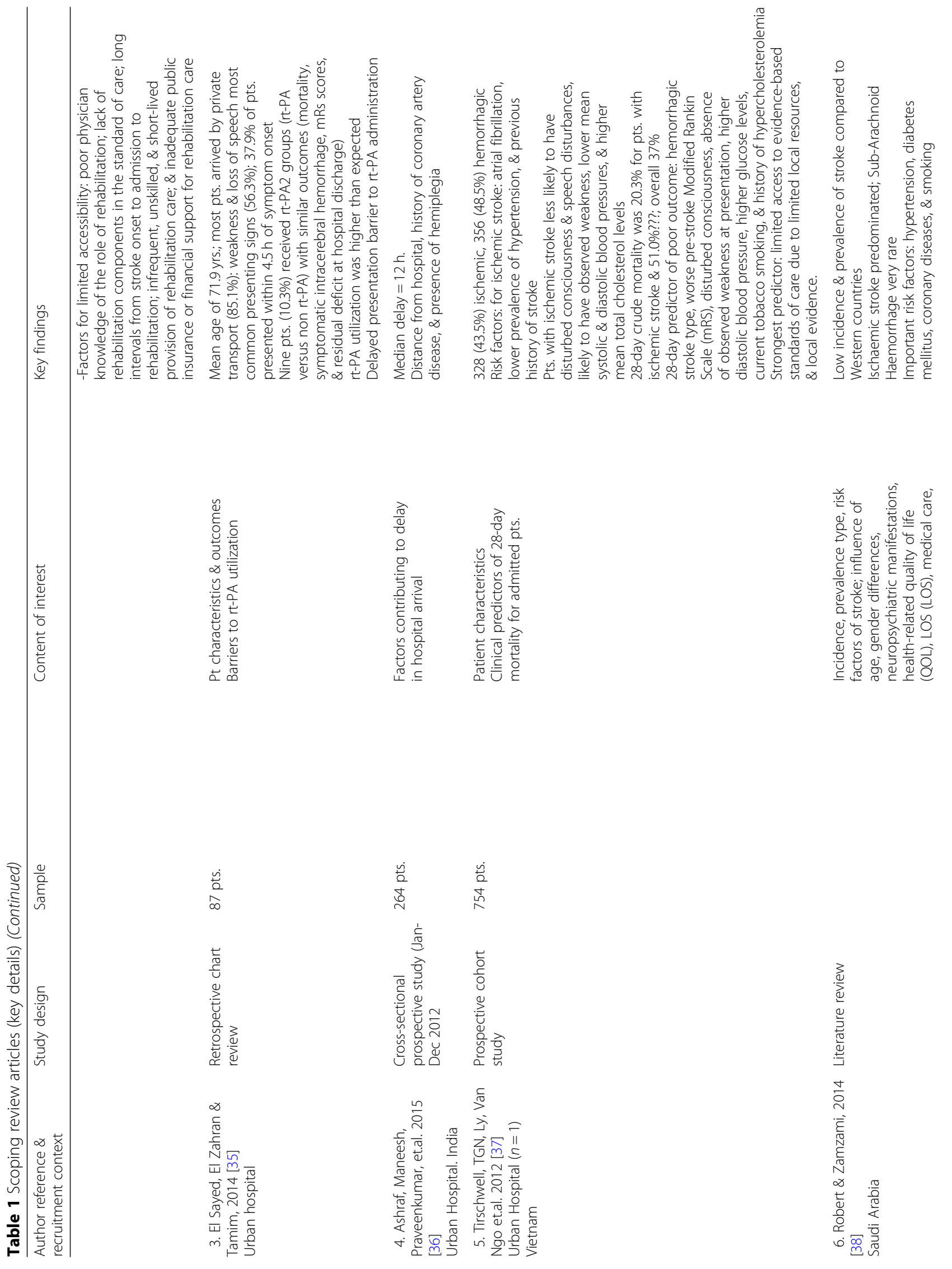




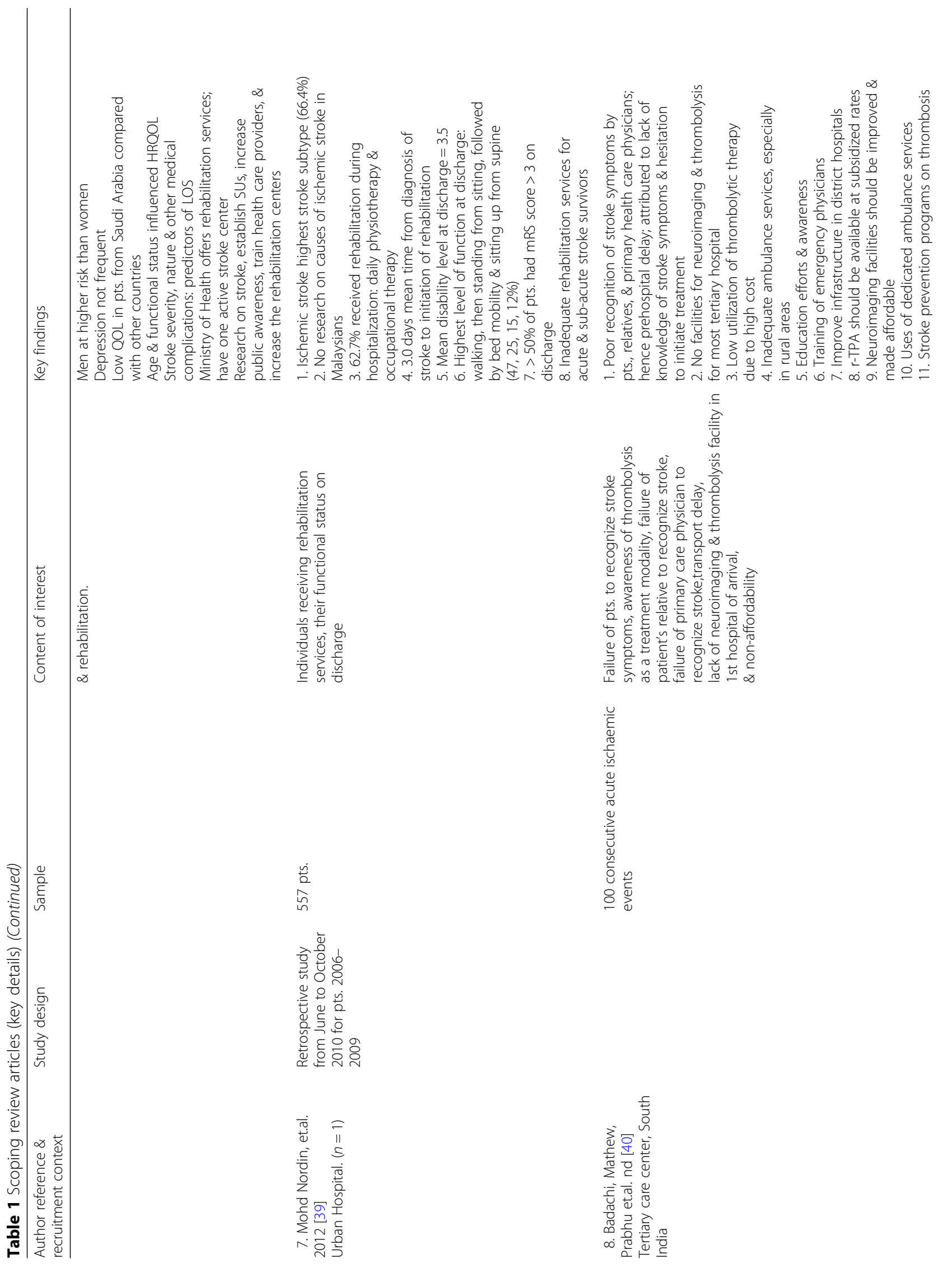




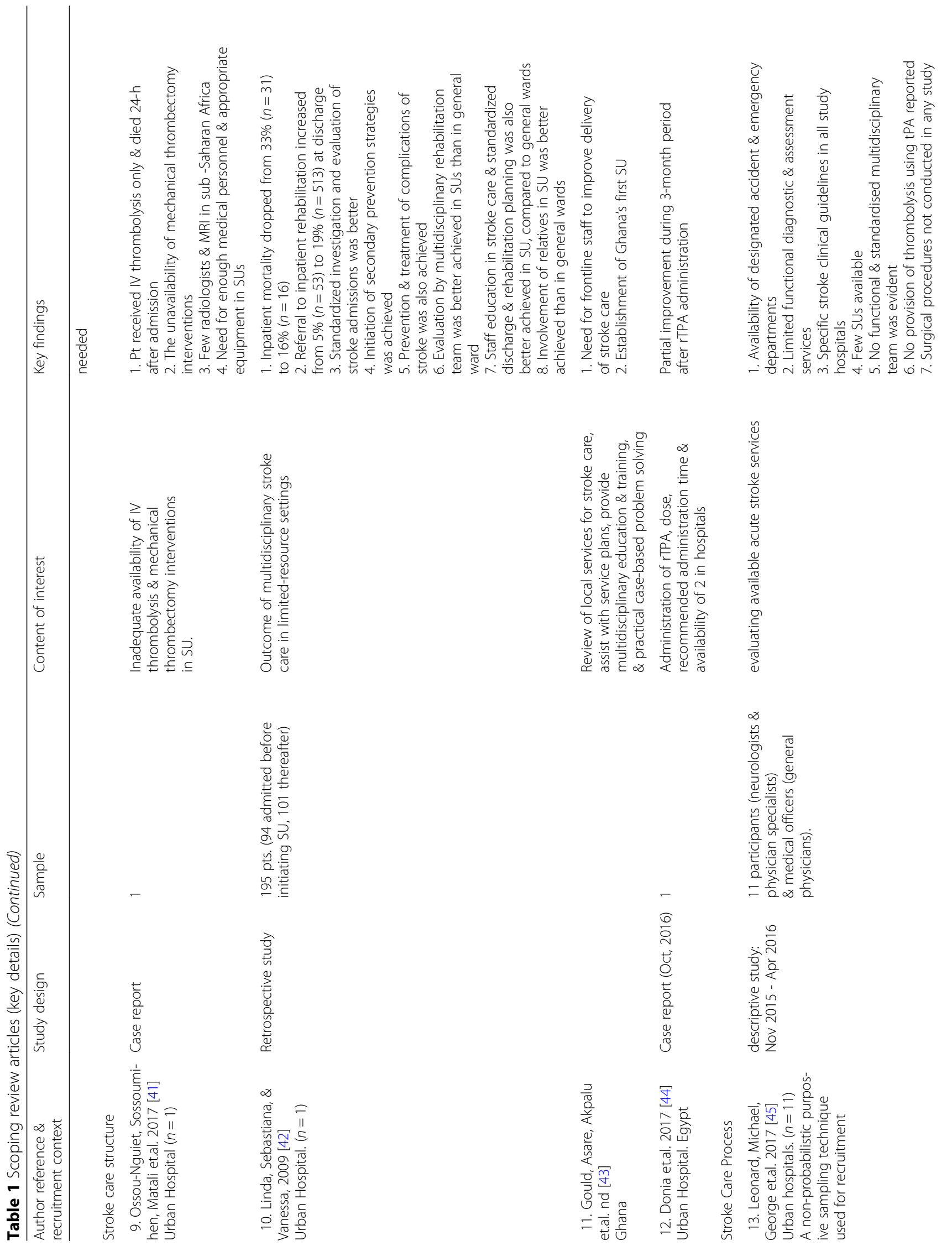




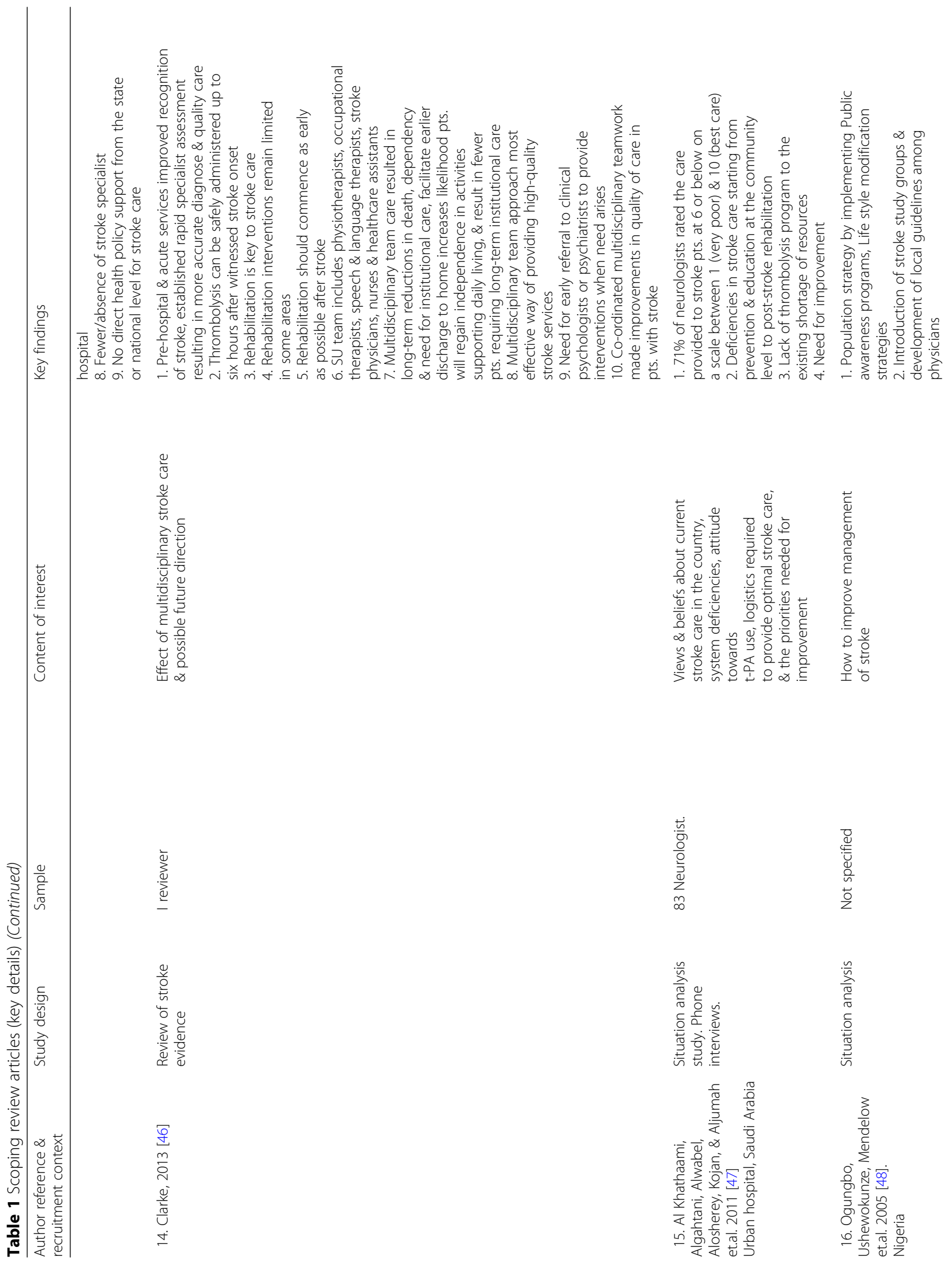




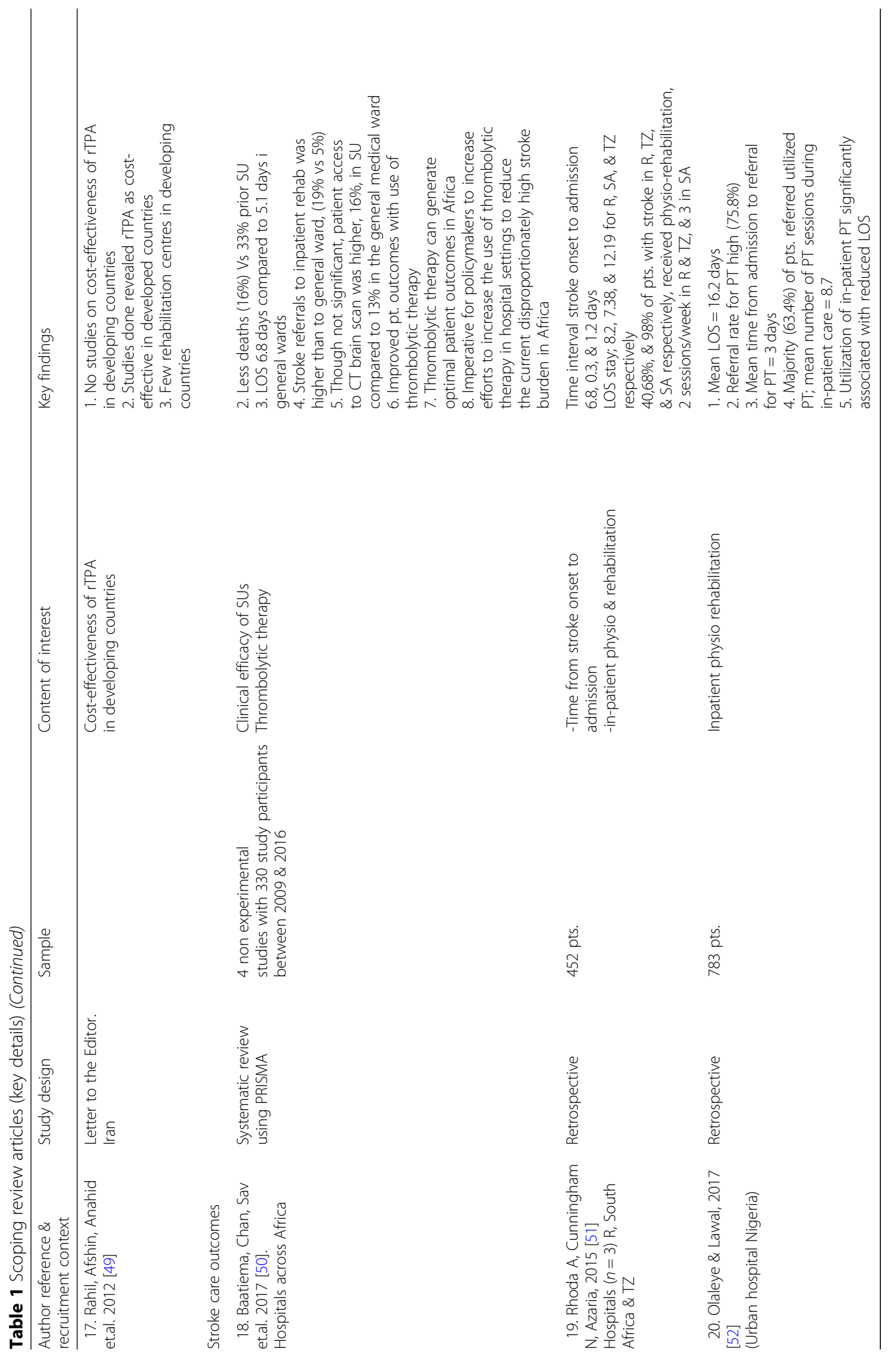




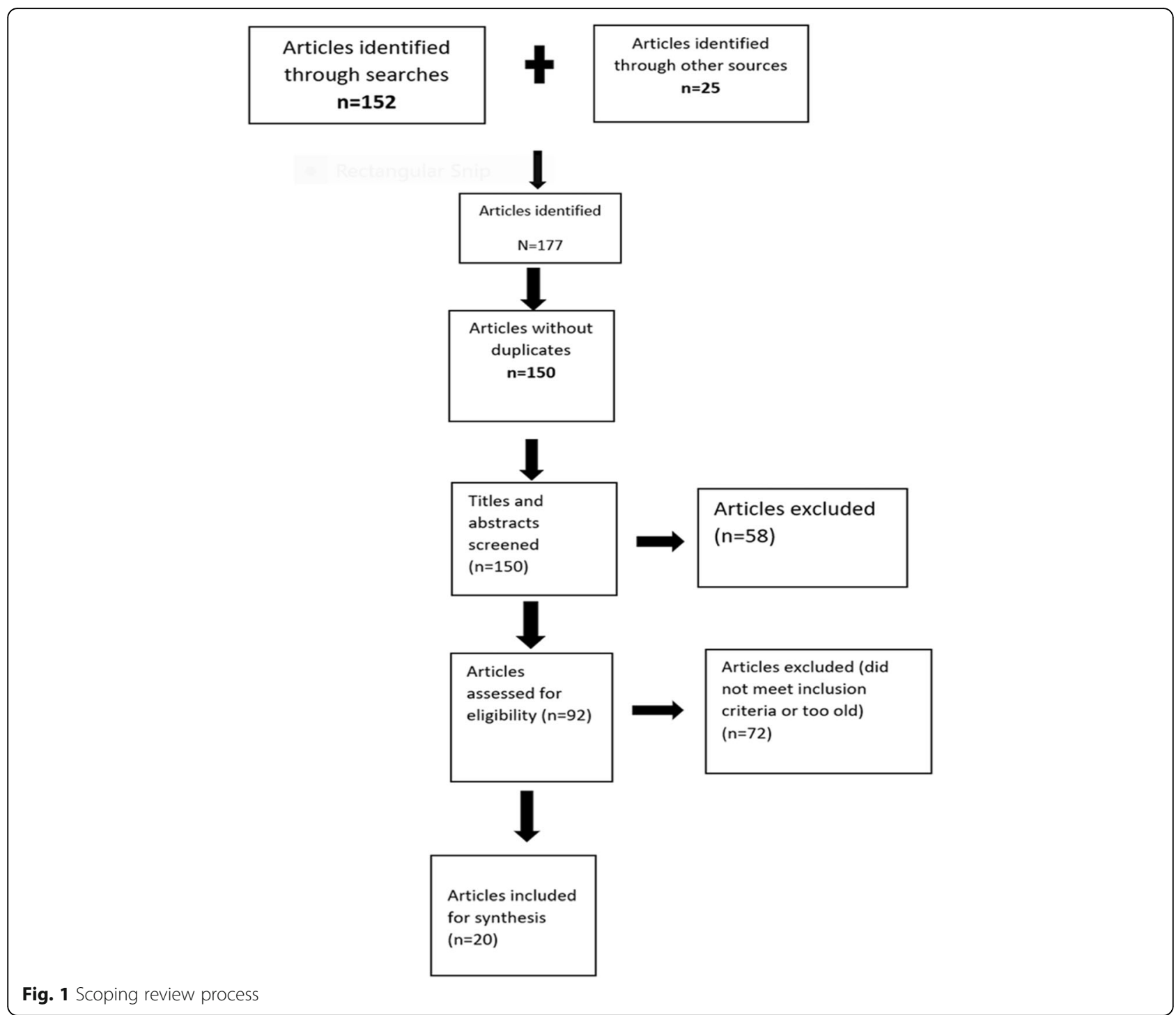

$42,45-48,50]$. Seven of them constituted the stroke care structure (Fig. 1). They were SU, accident and emergency department, multidisciplinary team, stroke specialists, neuroimaging, medication, and health care policies. There were few or no SUs in any of the settings within the LMICs [47]. The availability of designated accident and emergency departments that triage patients in LMICs, with specific clinical guidelines and functional and standardized multidisciplinary teams was associated with optimal stroke-care practice [45]. There are, however, few specialist health care workforces for acute stroke care both in number and variety [45] to constitute multidisciplinary teams. This type of teamwork was reported as the most effective way of providing highquality stroke services, even in less-resourced LMICs [46]. There were no facilities for neuroimaging and thrombolysis for many tertiary hospitals, inadequate ambulance services especially in rural areas, limited educational efforts and awareness, inadequate training of emergency care physicians [40], unavailability of mechanical thrombectomy interventions, and few radiologists and MRI technology in sub -Saharan Africa [41]. In those countries that had key radiological devices, such Computed Tomography (CT) scanners, there were effective diagnostic workups on patients with stroke. For example, 601 cases $(92.3 \%)$ were confirmed either by CT scan $(83.4 \%)$ or necropsy $(8.9 \%)$ as ischemic or hemorrhagic stroke, or subarachnoid hemorrhages [33]. Of note was that standardized investigation and evaluation of stroke assessment and admissions was much better after initiating multidisciplinary Stroke-Unit care, as established in some countries such as Ghana as a new development in the stroke care structure [45]. There was also limitation in availability of key medical supplies, such as rtPA in most LMICs [50]. There was poor physician knowledge of the role of rehabilitation; lack of 
rehabilitation components in the standard of care; a long interval from stroke onset to admission to rehabilitation; infrequent, unskilled, and short-lived provision of rehabilitation care; and inadequate public insurance or financial support for rehabilitation care [34].

In a related matter, countries such as Ghana had no direct health policy support from the state or national level for stroke care [45]. Studies recommended that policymakers could facilitate the utilization of thrombolytic therapy in hospital settings to reduce the current disproportionately high stroke burden in Africa [33]; rtPA could, therefore, be made available at subsidized rates; neuroimaging facilities could be improved and made affordable, in addition to use of dedicated ambulance services [40], and stroke prevention programs on thrombosis should be initiated [48]. Population strategy could focus on implementing public awareness programs, life-style modification strategies, the introduction of stroke study groups, development of local guidelines among physicians [48], upscaling rehabilitation services by training health care providers, and increasing the number of rehabilitation centers [38].

Some studies recommended a need for ministries of health and governments in LMICs to adopt and implement SUs for their reported impact on stroke outcomes $[41,42,50]$. For instance, the multidisciplinary teams afforded by SUs had been reported to have led to a drop in inpatient mortality, and increased referral to inpatient rehabilitation [42]. Additionally, standardized investigation and evaluation of stroke admissions was much better after initiating multidisciplinary SU care; initiation of secondary prevention strategies, prevention and treatment of complications of stroke, evaluation by a multidisciplinary rehabilitation team, staff education in stroke care and standardized discharge and rehabilitation planning and involvement of relatives were more easily achieved in SUs than in general wards $[42,50]$. Introduction of SUs was also associated with reduced LOS [50].

\section{Stroke care process}

The process of stroke was illustrated by 12 articles [33-36, 40-42, 46, 47, 49-52]. Six stroke care processes, illustrated in Fig. 2 consist of assessment and diagnosis, referral, intravenous thrombolysis, rehabilitation, and primary and secondary prevention strategies. Stroke assessment and diagnosis in LMICs was challenged by lack of proper stroke care structure $[40,41]$. Stroke assessment for diagnosis included patient history, physical examination, neurological examination and stroke scales, and diagnostic tests [34]. However, recognition of stroke had improved following the introduction of pre-hospital and acute services [36].

Five studies highlighted the management of ischemic stroke using rtPA. Intravenous thrombolysis was approved as an evidence-based treatment for acute ischemic stroke in some settings within the LMICs [34]. Although, there were no studies on the costeffectiveness of rtPA in developing countries, studies in developed countries revealed that rtPA was costeffective [49] in treating ischemic stroke. Improved

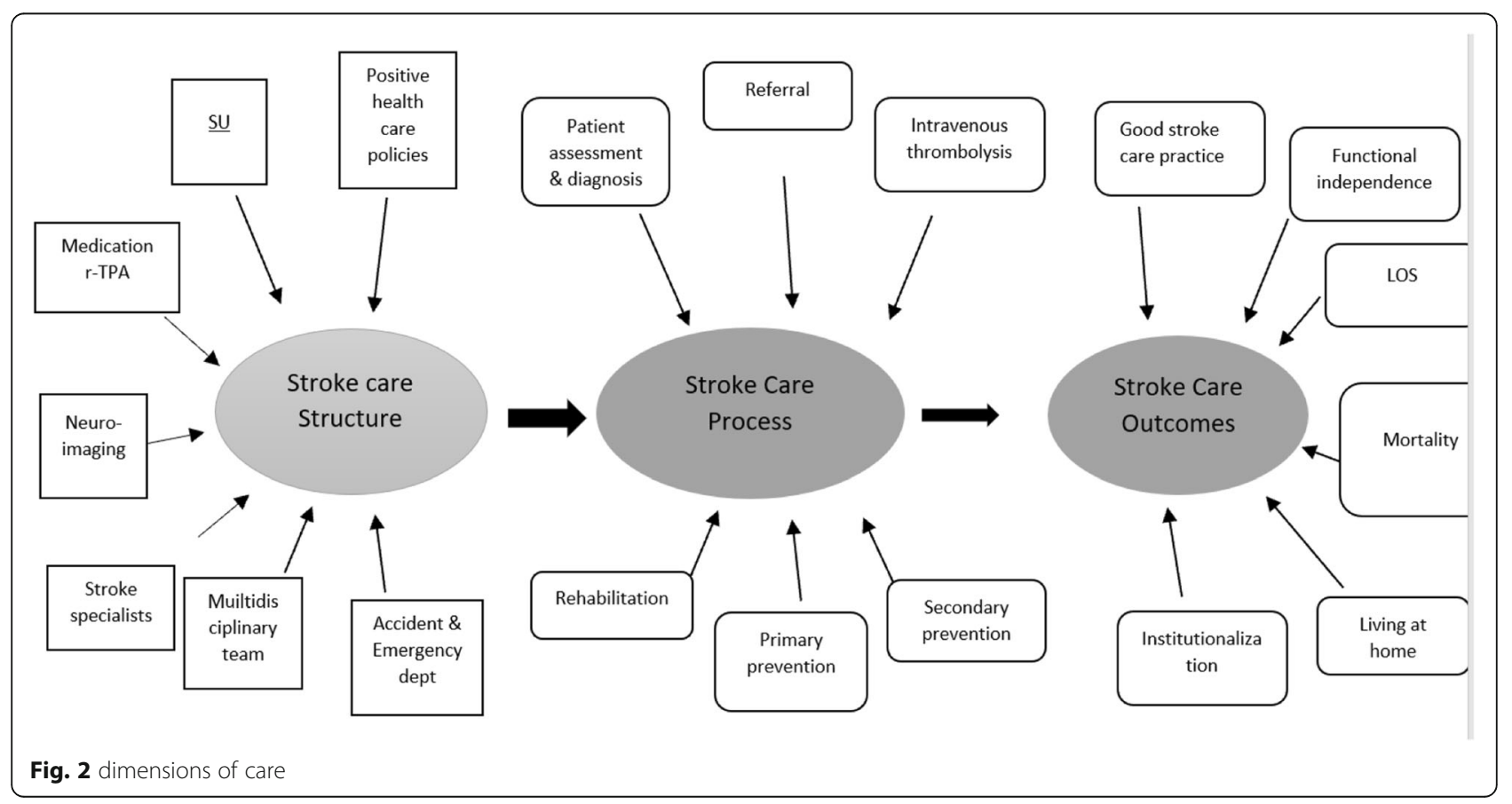


patient outcomes with the use of thrombolytic therapy could generate optimal patient outcomes in Africa [50], as lack of thrombolysis program was said to add to the existing shortage of resources [47]. Thrombolysis could be safely administered up to 6 hours after witnessed stroke onset [46]. However, delayed presentation to the hospital was the main barrier to rt-PA administration in Lebanon [46].

Rehabilitation services for patients with stroke was highlighted in seven articles. Of importance was the common finding that rehabilitation represented a key part of stroke care for the majority of patients. However, despite much research revealing the necessity of rehabilitation, the intervention remained limited in most LMICs. Recommendations were for rehabilitation to commence as early as possible after a witnessed stroke. SU team or just stroke team (in absence of SU) included physiotherapists, occupational therapists, speech and language therapists, stroke physicians, nurses and healthcare assistants [46]. Referral to in-patient rehabilitation varied depending on the approaches to stroke care, as introduction of SUs and multidisciplinary team in some LMICs was associated with a huge increase in referrals. The mean time from admission to referral for physiotherapy was 3 days [42]. The majority of patients referred utilized physiotherapy and the mean number of physiotherapy sessions received during inpatient care in the sampled urban hospitals varied. For example, physiotherapy was utilized 2 sessions per week in Nigeria [52], 2 sessions per week in Rwanda and Tanzania respectively, and 3 in South Africa [51].

Two reports highlighted stroke prevention strategies, with approaches including blood pressure control, promotion and maintenance of healthy lifestyles (i.e., not smoking or smoking cessation for smokers, no binge drinking, being physically active, and a healthy diet with adequate fruit and vegetable intake, reduced dietary trans-fats, and reduced sodium [33]. Secondary prevention of stroke, on the other hand, included blood pressure control, antiplatelet and lipid-lowering therapy, homocysteine-lowering therapy, and self-management and family support [34].

\section{Stroke care outcomes}

Regarding stroke care outcomes, 7 studies (34, 35, 39, $41,47,49)$ reported a total of six dimension of strokecare outcomes, illustrated on the right side of Fig. 1. They were quality of stroke care practice, functional independence, length of hospital stay (LOS), mortality, living at home, and institutionalization. Of note, was LMICs with better structure and processes of care such as availability of SU, patients were more likely to be alive, independent, and living at home 1 year after stroke [34]. On the other end, LMICs with no requisites had unsatisfactory or poor stroke service delivery [47] and poor stroke care practice [45]. Thrombolysis [45], mechanical thrombectomy in combination with pharmacological thrombolysis when indicated improved functional outcomes [34]. Utilization of inpatient physiotherapy (PT) was significantly associated with reduced LOS [52], and reduced mortality [38]. Absence of rehabilitation on the other hand was associated with reduced level of function, evidenced by increased modified Rankin scale (mRs) score [39]. Studies had further shown that a structural dimension such as multidisciplinary stroke care teams resulted in long-term reductions in death, dependency and the need for institutional care, facilitated earlier discharge to the home, increased the likelihood that patients would regain independence in activities that support daily living, and resulted in fewer patients requiring long-term institutional care in some settings within LMIC [46].

\section{Discussion}

In this paper, we extracted data from twenty articles that highlighted stroke care in LMICs with the guide of the DM on quality of care as a conceptual framework. Nineteen dimensions of stroke care emerged, covering stroke-care SPO. Seven of the 19 dimensions that emerged were structural. They included a SU, accident and emergency department, multidisciplinary team, stroke specialists, neuroimaging, medication, and health care policies [33, 34, 38, 40-42, 45$48,50]$. Structurally, this review showed that there were few or no SUs in various settings within LMICs. As a result, stroke service delivery in those areas was unsatisfactory or poor [47]. The development and running of SUs was a key recommendation in most countries including the developing ones [21]. In LMICs, fast-tracking was needed for the establishment of SUs to revolutionize stroke care provision, with the great possibility of improving stroke outcomes [53]. Availability of designated accident and emergency departments with specific stroke clinical guidelines and functional and standardized multidisciplinary teams for acute stroke care were associated with good stroke care practice [45]. But the LMICs are grappling with the number and variety of stroke specialists, for example, very few neurologists and almost no speech therapists to form and run efficient teams [45]. There is a need for those countries to develop a competitive edge through provision of equal opportunities for career advancement, lifelong learning, and to develop policies that promote loyalty and retention [54]. Further on, this study highlighted that most LMICs countries, had inadequate facilities for neuroimaging and thrombolysis, inadequate ambulance services especially in rural areas, limited education efforts and awareness about stroke, inadequate training of emergency physicians [40], and inadequate public 
insurance or financial support for rehabilitation care [34]. There is a pressing need for health care providers to lobby and secure direct health policy support from the state or national level for stroke care [45] to minimize these challenges.

Six dimensions of stroke care processes that emerged in this review were assessment and diagnosis, referral, intravenous thrombolysis, rehabilitation, and primary and secondary prevention strategies [33-35, 41, 42, 46-52]. Undoubtedly, the structural limitations in LMICs has a bearing on stroke care stroke processes. This review showed that stroke assessment and diagnosis is challenged by inadequate availability of neuroimaging [40, 41]. The role for intravenous thrombolysis as evidence-based treatment for acute ischemic stroke is known [34]. It is cost-effectiveness even in LMICs [49] via its generation of optimal patient outcomes in Africa [50], and that, lack of the same adds to the existing shortage of resources [47]. We, therefore, share the observation that there is a great need for ministries of health and governments to embrace "the trends", strengthen radiology departments and adopt thrombolysis therapy in stroke care protocols. What was also agreeable in this review was the common finding that rehabilitation represents a key part of stroke care, although, clearly, the interventions remain extremely limited in most LMICs. Research recommends that rehabilitation should commence as early as possible after stroke, within 24 to $48 \mathrm{~h}$ [46]. However, access to rehabilitation services remains low in LMICs, due, mostly to structural roadblocks such as limitation in number and variety of rehabilitation professionals [40, 41]. This review highlighted the need for a two-tier stroke-prevention strategy: primary preventive approaches for stroke, which included blood pressure control and promotion and maintenance of healthy lifestyle [33], and secondary prevention strategies such as blood pressure control, antiplatelet and lipid-lowering therapy, homocysteine-lowering therapy, self-management, and family support [34]. Primary preventive strategies remained key to the prevention of stroke and must be embraced in all efforts aimed at improving stroke care.

The last six dimensions that emerged were stroke care outcomes that included quality of stroke care practice, functional independence, LOS, mortality, living at home, and institutionalization. Of note was that the LMICs with better structure and processes of care such as the availability of a $\mathrm{SU}$, patients were more likely to be alive, independent, and living at home 1 year after stroke [34]. Comparatively, countries with no requisites had consequent poor stroke service delivery [47]. In the LMICs where thrombolysis was administered in combination with mechanical thrombectomy there was significant improvement in functional outcome $[34,45]$. Further, rehabilitative therapy was associated with reduced LOS [52], and reduced mortality [38]. On the other hand, reduced level of function was reported in the situations of absent rehabilitative treatment [39]. Additionally, where multidisciplinary teams were implemented, long-term reductions in death, dependency, and early-discharge was reported [46]. There is, therefore, a compelling need for improved structure: allocation of resources, appropriately trained personnel, and recognition of the importance of an integrated team approach to the delivery of stroke care in LMICs. This will ultimately lead to the improved delivery of stroke care [41]. and significantly improved outcomes. Many lives could be saved and the quality of life improved for the current and future generations.

This scoping review focused on a broad research field of stroke care. And 2010 to 2017 is reasonably a wide range of publication year, having only 20 articles as meeting inclusion criteria sounds spurious. However, the included articles were very specific to the study question and so could be reflective of stroke care in LMICs. Lack of strict adherence to methodological quality that goes with scoping review might affect the quality of this review. Constant checks with research team members added rigor to the study process. Additionally, the study precluded addressing issues related to personnel availability, program funding, and training institutions across the LMICs to train stroke care specialists.

\section{Conclusions}

Inconsistencies exist in the way stroke care is advanced in LMICs. This is reflected in unsatisfactory stroke care structure, processes and outcomes in some settings of study area. There is a need for stroke care settings to adopt stroke care quality improvement strategies. Health ministry and governments need to decisively face stroke burden by setting policies that advance improved care of patients with stroke [45]. SUs and rtPA administration could be considered as both a structural and process necessity. It is clearly an imperative in LMICs such as Malawi for the care of patients with acute stroke, whose numbers are increasing exponentially.

\section{Abbreviations \\ CINNAHL: Cumulative Index to Nursing and Allied Health Literature; CT: Computed Tomography; DM: Donabedian Model; LMICs: Low- and Middle-Income Countries; LOS: Length of Hospital Stay; MESH: Medical subject headings; MRI: Magnetic Resonance Imaging; mRs: Modified Rankin scale; PT: Physiotherapy; rtPA: Recombinant Tissue Plasminogen Activator; SPO: Structures, Processes, and Outcomes; SU: Stroke Units}

\section{Acknowledgements}

This research was part of the major PHD project at the University of the Western cape where project approval was granted. We thank our colleagues from the Medical Rehabilitation college who provided insight and expertise that greatly assisted the research through providing technical assistance during data searching and ICT service.

We thank Leslie Glickman, PHD for her great comments, insights in some areas of the study, and language editing that greatly improved quality of the manuscript. Stella Mpezeni, PT; Haules Zaniku, PT, Justice Amadi, PT and Eunice Muvindi, OT and Fungai Makotore, OT for peer support during literature search, data extraction and write-up.

We would like show our gratitude to Cedric Pahuwa, MPH, principal Medical Rehabilitation College for the material and time support to see this project to the end. 


\section{Authors' contributions}

GC: Primary author, conceived of the study, literature review, write up. AR primary supervisor, expertise regarding the course of the study. The authors contributed to refinement of the study protocol and approved the final manuscript.

\section{Funding}

This work relied on the author's saving and had no formal funding.

\section{Availability of data and materials}

All data generated or analyzed during this study are included in this manuscript. Specific articles that were analyzed, if needed, can be obtained from the corresponding author.

\section{Ethics approval and consent to participate}

Ethics approval was received from the University of the Western Cape: registration number 15/6/31; College of Medicine Research and Ethics Committee (COMREC) of the University of Malawi: approval number P.10/15/ 1819. As this is a scoping review there was no need to seek approval for participation.

\section{Consent for publication}

Not applicable.

\section{Competing interests}

The authors declare that they have no competing interests.

Received: 18 May 2019 Accepted: 17 October 2019

Published online: 04 November 2019

\section{References}

1. Strong K, Mathers C, Leeder S, Beaglehole R. Preventing chronic diseases: how many lives can we save? Lancet. 2005;366:1578-82.

2. Duncan PW, Zorowitz R, Bates B, Choi JY, Glasberg JJ, Graham GD, et al. Management of Adult Stroke Rehabilitation Care: a clinical practice guideline. Stroke. 2005 Sep;36(9):e100-43.

3. Simbar M, Nahidi F, Akbarzadeh A. Quality of antenatal Care in Health Centers related to medical science University of Shahid beheshti. Ira J Payesh. 2010;11(4):529-44.

4. Donabedian A. The quality of care, how can it be assessed? Jama. $1988 \mathrm{Sep}$ 23;260(12):1743-8

5. McDonald KM, Sundaram V, Bravata DM, Lewis R, Lin N, Kraft SA, et al. Closing the quality gap: a critical analysis of quality improvement strategies. Vol. 7: Care Coord.

6. Berwick D, Fox DM. "Evaluating the quality of medical care": Donabedian's classic article 50 years later. Milbank Q. 2016;94(2):237-41.

7. Mullan F. A founder of quality assessment. interview; 2001.

8. Ameh S, Gómez-Olivé FX, Kahn K, Tollman SM, Klipstein-Grobusch K. Relationships between structure, process and outcome to assess quality of integrated chronic disease management in a rural south African setting: applying astructural equation model. BMC Health Serv Res. 2017;17(1):229.

9. Casaubon LK, Boulanger JM, Glasser E, Blacquiere D, Boucher S, Brown K, et al. Canadian stroke best practice recommendations: acute inpatient stroke care guidelines, update 2015. Int J Stroke. 2016;11(2):239-52.

10. Bernhardt J, English C, Johnson L, Cumming TB. Early mobilization after stroke. Early Adoption but Limited Evidence. Stroke. 2015 Apr;46(4):1141-6.

11. Lauck SB, Kwon JY, Wood DA, Baumbusch J, Norekvål TM, Htun N, et al. Avoidance of urinary catheterization to minimize in-hospital complications after transcatheter aortic valve implantation: an observational study. Eur J Cardiovasc Nurs. 2018;17(1):66-74.

12. Mahawish KM, Heikinheimo T. Stroke in Malawi - what do we know about it and how should we manage it? Malawi Med J. 2010;22(1):24-8.

13. Middleton S, Grimley R, Alexandrov AW. Triage, Treatment, and Transfer: Evidence-Based Clinical Practice Recommendations and Models of Nursing Care for the First 72 Hours of Admissionto Hospital for Acute Stroke. Stroke. 2015;46:e18-25.

14. Trialists'Collaboration SU. Organised inpatient (stroke unit) care for stroke. Cochrane Database Syst Rev. 2013;9.

15. Wardlaw JM, Murray V, Berge E, Del Zoppo GJ. Thrombolysis for acute ischaemic stroke. Cochrane Database Syst Rev. 2009;2009:4.
16. Hacke W, Kaste M, Bluhmki E, Brozman M, Dávalos A, Guidetti D, et al. Thrombolysis with alteplase 3 to 4.5 hours after acute ischemic stroke. N Engl J Med. 2008 Sep;359(13):1317-29.

17. Sandercock PA, Counsell C, Tseng M, Cecconi E. Oral antiplatelet therapy for acute ischaemic stroke (review). Cochrane Database Syst Rev. 2014;3.

18. Vahedi K, Hofmeijer J, Juettler E, Vicaut E, George B, Algra A, et al. Early decompressive surgery in malignant infarction of the middle cerebral artery: a pooled analysis of three randomised controlled trials. Lancet Neurol. 2007; 6(3):215-22

19. Donnan GA, Davis SM, Parsons MW, Ma H, Dewey HM, Howells DW. How to make better use of thrombolytic therapy in acute ischemic stroke. Nat Rev Neurol. $2011 \mathrm{Jul} ; 7(7): 400-9$.

20. Scottish Intercollegiate Guidelines Network. Management of patients with stroke: rehabilitation, prevention and management of complications, and discharge planning: a national clinical guideline. 2010.

21. Baatiema L, Aikins AD, Sav A, Mnatzaganian G, Chan CK, Somerset S. Barriers to evidence-based acute stroke care in Ghana: a qualitative study on the perspectives of stroke care professionals. BMJ Open. 2017;7(4).

22. Yew KS, Cheng EM. Diagnosis of acute stroke. Am Fam Physician. 2015 Apr; 91(8):528-36.

23. Morgenstern LB, Lisabeth LD, Mecozzi AC, Smith MA, Longwell PJ, McFarling DA, et al. A population-based study of acute stroke and TIA diagnosis. Neurology. 2004 Mar;62(6):895-900.

24. Imam I, Olorunfemi G. Clinical diagnosis of stroke: need for audit. Ann Afr Med. 2004;3(4):167-9.

25. Feigin VL, Lawes CM, Bennett DABCSL, Parag V. Worldwide stroke incidence and early case fatality reported in 56 population-based studies: a systematic review. Lancet Neurol. 2009 Apr;8(4):355-69.

26. Langhorne $P$, de Villiers $L$, Pandian JD. Applicability of stroke-unit care to low-income and middle-income countries. Lancet Neurol. 2012;11(4):341-8.

27. Baatiema L, Otim M, Mnatzaganian G, Aikins AD, Coombes J, Somerset S. Towards best practice in acute stroke care in Ghana: a survey of hospital services. BMC Health Serv Res. 2017;17(1):108.

28. Arksey H, O'Malley L. Scoping studies: towards a methodological framework. Int J Soc Res Methodol. 2005;8(1):19-32.

29. Joanna Briggs Institute. JBI Reviewers Manual: Methodology for JBI-Scoping Reviews. 2015.

30. World Bank. World Bank high-income economy. [Online]. [cited 2019 February 15 Available from: https://en.wikipedia.org/wiki/World_Bank_high-income_economy.

31. Unicef. Convention on the Rights of the Child. 1989.

32. Halas G, Schultz AS, Rothney J, Goertzen L, Wener P, Katz A. A scoping review protocol to map the research foci trends in tobacco control over the last decade. BMJ Open. 2015;5(1).

33. Damasceno A, Gomes J, Azevedo A, Carrilho C, Lobo V, Lopes H, Madede T, Pravinrai P, Silva-Matos C, Jalla S, Stewart S. An epidemiological study of stroke hospitalizations in Maputo, Mozambique: a high burden of disease in a resource-poor country. Stroke. 2010;41(11):2463-9.

34. Yan LL, Li C, Chen J, Miranda JJ, Luo R, Bettger J, et al. Prevention, management, and rehabilitation of stroke in low- and middle-income countries. eNeurologicalsci. 2016;2:21-30.

35. El Sayed MJ, El Zahran T, Tamim H. Acute stroke care and thrombolytic therapy use in a tertiary care center in Lebanon. Emerg Med Int. 2014;2014.

36. Ashraf W, Maneesh M, Praveenkumar R, Saifundheen K. Factors delaying hospital arrival of patients with acute stroke. Ann Indian Acad Neurol. 2015; 18(2):162.

37. Tirschwell DL, Ton TG, Ly KA, Van Ngo Q, Vo TT, Pham CH, Longstreth WT, Fitzpatrick AL. A prospective cohort study of stroke characteristics, care, and mortality in a hospital stroke registry in Vietnam. BMC neurology. 2012 Dec; 12(1):150.

38. Robert AA, Zamzami MM. Stroke in Saudi Arabia; A review of the recent literature. Pan Afr Med J. 2014:17(14).

39. Mohd Nordin NA, Aziz NA, Alkaff SE, Sulong S, Aljunid S. Rehabilitation for patients after stroke in a tertiary hospital: is it early and intensive enough. Int J Ther Rehabil. 2012;19(11):603-11.

40. Badachi S, Mathew T, Prabhu A, Nadig R, Sarma GR. Hurdles in stroke thrombolysis: Experience from 100 consecutive ischemic stroke patients. Annals of Indian Academy of Neurology. 2015;18(4):415.

41. Ossou-Nguiet PM, Sossoumihen LL, Matali E, Mpandzou GA, Motoula Latou $\mathrm{DH}$, Sounga Bandzouzi EP, et al. Stroke in Sub-Saharan Africa, from Thrombolysis to Decompressive Craniectomy: Case Report. Austin J Cerebrovasc Dis Stroke. 2017;(3):4. 
42. Linda DV, Sebastiana ZK, Vanessa CB. Does multidisciplinary stroke care improve outcome in a secondary-level hospital in South Africa? Int I Stroke. 2009;4:89-93.

43. Gould A, Asare H, Akpalu A, Cullen L, Easton S, Jarrett D, Johnson L, Kirk H, Spice C, Williams J. Development of stroke care in Ghana. International Journal of Stroke. 2011 Apr;6(2):150-1.

44. Donia AF, Elbialy NM, Elsaid NA, Refaie AF. The first reported case of acute ischemic stroke treated with tissue plasminogen activator at Mansoura University, Egypt. The Egyptian Journal of Critical Care Medicine. 2017 Dec 1;5(3):99-100.

45. Leonard B, Michael O, George M, Ama DGA, Judith C, Shawn S. Towards best practice in acute stroke care in Ghana: a survey of hospital services. BMC Health Serv Res. 2017;17(108).

46. Clarke DJ. The role of multidisciplinary team care in stroke rehabilitation. Prog Neurol Psychiatry. 2013:17(4):5-8

47. Al Khathaami AM, Algahtani H, Alwabel A, Alosherey N, Kojan S, Aljumah M. The status of acute stroke care in Saudi Arabia: an urgent call for action! International Journal of Stroke. Int J Stroke. 2011;6(1):75-6.

48. Ogungbo B, Ogun A, Ushewokunze S, Mendelow A, Walker R, Rodgers H. How can we improve the management of stroke in Nigeria, Africa? Table Contents. 2005;24(2):9.

49. Rahil AS, Afshin BH, Anahid S, Salvador CF. Letter to the editor. Int J Stroke. 2012;7.

50. Baatiema L, Chan CKY, Sav A, Somerset S. Interventions for acute stroke management in Africa: a systematic review of the evidence. Syst Rev. 2017;6:213.

51. Rhoda A, Cunningham N, Azaria S, Urimubenshi G. Provision of inpatient rehabilitation and challenges experienced with participation post discharge: quantitative and qualitative inquiry of African stroke patients. BMC Health Serv Res. 2015;15(1):423.

52. Olaleye OA, Lawal Zl. Utilization of physiotherapy in the continuum of stroke care at a tertiary hospital in Ibadan, Nigeria. Afr Health Sci. 2017; 17(1):79-87.

53. Feigin $\mathrm{VL}$, Forouzan $\mathrm{MH}$, Krishnamurthi $\mathrm{R}$, Global Burden of Diseases, Injuries,and Risk Factors Study 2010 (GBD 2010) and the GBD Stroke Experts Group. Global and regional burden of stroke during 1990-2010: findings from the Global Burden of Disease Study 2010. Lancet. 2014;383:243-54.

54. Marchal B, Brouwere VD, Kegels G. Viewpoint: HIV/AIDS and the health workforce crisis: what are the next steps? Tropical Med Int Health. 2005; 10(4):300-4

\section{Publisher's Note}

Springer Nature remains neutral with regard to jurisdictional claims in published maps and institutional affiliations.

Ready to submit your research? Choose BMC and benefit from:

- fast, convenient online submission

- thorough peer review by experienced researchers in your field

- rapid publication on acceptance

- support for research data, including large and complex data types

- gold Open Access which fosters wider collaboration and increased citations

- maximum visibility for your research: over $100 \mathrm{M}$ website views per year

At $\mathrm{BMC}$, research is always in progress.

Learn more biomedcentral.com/submissions 